\title{
Clinical Characteristics of Patients with Peripheral Pulmonary Embolism
}

\author{
Seung-Ick Cha ${ }^{a}$ Kyung-Min Shin ${ }^{b}$ Jung-Woo Lee ${ }^{a}$ Jongmin Lee ${ }^{b}$ \\ Shin-Yup Lee ${ }^{a}$ Chang-Ho Kim ${ }^{a}$ Jae-Yong Park ${ }^{a}$ Tae-Hoon Jung ${ }^{a}$ \\ Departments of ${ }^{\mathrm{a}}$ Internal Medicine, and ${ }^{\mathrm{b}}$ Radiology, Kyungpook National University School of Medicine, \\ Daegu, Korea
}

\section{Key Words}

Computed tomography • Pulmonary arteries • Pulmonary

embolism • Treatment clusions: Patients with ISSPE may have a more benign clinical presentation, as compared to the central type, and may follow a good clinical course without mortality or recurrence.

Copyright $\odot 2010$ S. Karger AG, Basel

\begin{abstract}
Background: The clinical relevance of emboli limited to the segmental or sub-segmental pulmonary arteries and the role of anticoagulation in patients with these conditions remains to be clarified. Objectives: To determine the clinical characteristics and treatment outcomes of peripheral pulmonary embolism (PE), and in particular, isolated sub-segmental PE (ISSPE). Methods: We reviewed the data for 334 patients who were diagnosed with a PE by computed tomographic (CT) pulmonary angiography and indirect CT venography. Results: All patients were classified into one of three groups: central (245 patients, $73.4 \%$ ); segmental (67 patients, $20.1 \%$ ), and sub-segmental (22 patients, 6.6\%). An incidental CT finding (63.6\%) was the most common presentation in the segmental and sub-segmental groups. Compared with the central group, the sub-segmental group had less frequent proximal deep venous thrombosis (14 vs. 47\%, Bonferroni's corrected $p=0.002$ ), and greater preservation of oxygenation levels $(p<0.05)$ without hemodynamic instability. The recurrence of $\mathrm{PE}$ and deaths related to PE did not occur in the sub-segmental group, although approximately $30 \%$ of the patients did not receive anticoagulation therapy. Con-
\end{abstract}

\section{Introduction}

In the early 1990s when helical computed tomography (CT) was introduced for the diagnosis of a pulmonary embolism (PE) [1], it could reliably detect a central PE but was limited in excluding a small PE $[2,3]$. Recently, the advent of multi-detector row CT (MDCT) improved visualization up to the levels of the segmental and sub-segmental pulmonary arteries [4], thereby enhancing more confidently the diagnosis of smaller PEs [5]. Currently, MDCT has replaced scintigraphy as the imaging study of choice in the diagnosis of PEs in many institutions [6]. In 2007, MDCT angiography fulfilled the conditions to replace pulmonary angiography as the reference standard for the diagnosis of an acute PE [7].

Clinicians' interest in small PEs, particularly PEs limited to the sub-segmental arteries (isolated sub-segmental PE, ISSPE) dates back to the data based on conventional pulmonary angiography [8]. Peripheral PEs, in which emboli do not extend proximally beyond the seg-

\section{KARGER}

Fax +41613061234 E-Mail karger@karger.ch www.karger.com
(C) 2010 S. Karger AG, Basel

0025-7931/10/0806-0500\$26.00/0

Accessible online at:

www.karger.com/res
Seung-Ick Cha, MD

Department of Internal Medicine, Kyungpook National University Hospital

50 Samduk 2-Ga, Jung-Gu

Daegu 700-712 (South Korea)

Tel. +82 53420 6412, Fax +82 53426 2046, E-Mail sicha@ knu.ac.kr 
mental or sub-segmental pulmonary arteries, has not uncommonly been detected on MDCT scans regardless of whether it is incidentally detected or diagnosed in suspected patients. Recently, the clinical relevance of peripheral PEs and the role of anticoagulation in these patients have been questioned in several reports $[5,9,10]$. In a previous study [5], patients with ISSPE less frequently had dyspnea, a high clinical probability of $\mathrm{PE}$, and proximal deep venous thrombosis (DVT), as compared with segmental or more proximal groups. Among the 30 patients with ISSPE, eight were left untreated and none of them experienced a thromboembolic event during the 3-month follow-up period. However, these studies have mostly been focused on the radiologic aspects and data regarding clinical features are sparse or have been indirectly obtained [5]. The aim of this study was to determine the clinical characteristics and treatment outcomes of peripheral PEs, especially ISSPEs.

\section{Materials and Methods}

\section{Study Population}

We searched the computer database of the Kyungpook National University Hospital (a tertiary referral center in Daegu, South Korea) for patients $\geq 18$ years of age who underwent CT pulmonary angiography and indirect CT venography and were diagnosed with a PE at that institution between September 2003 and December 2008. A total of 334 patients with PEs were collected and classified into 3 groups by the largest PE-involved pulmonary arteries: central (main trunk, right or left pulmonary artery, intermediate arteries, or lobar arteries); segmental, and subsegmental (fig. 1). To determine the locations of the most proximal pulmonary arteries in which emboli were detected, CT scans were reviewed separately by 2 experienced radiologists (K.M.S. and J.L.) who were blinded to the patients' clinical information. In case of discrepancies in their readings, a final decision was reached by consensus. This study was approved by the institutional review board of the KNUH, and written informed consent was waived because this study was retrospective.

\section{Clinical Data}

The following baseline data of the patients were recorded at presentation: age, gender, smoking history, body mass index (BMI), presenting manifestations, duration of symptoms, and presence or absence and location of DVT. To assess the clinical probability, we retrospectively scored the clinical prediction rules using the Wells [11] and Revised Geneva scores [12] from the medical records. The risk factors for PEs and comorbid conditions were reviewed. A patient who had smoked at least once a day for $>1$ year in his or her lifetime was regarded as an ever-smoker. The cumulative cigarette dose (pack years) was calculated using the following formula: pack years $=$ packs per day $\times$ years smoked.

Data of arterial blood gas analysis, including partial pressure of oxygen in arterial blood $\left(\mathrm{PaO}_{2}\right)$, oxygen saturation in arterial blood $\left(\mathrm{SaO}_{2}\right)$, and alveolar-arterial oxygen difference $\mathrm{P}(\mathrm{A}-\mathrm{a}) \mathrm{O}_{2}$, se- rum biomarkers of PEs including the levels of N-terminal-pro-Btype natriuretic peptide (NT-proBNP), D-dimer, troponin-I, and creatine kinase-MB (CK-MB), and the presence of hypotension (systolic blood pressure $<90 \mathrm{~mm} \mathrm{Hg}$ ), T-wave inversion on the precordial leads of the electrocardiogram (ECG), and right ventricular (RV) dysfunction on echocardiography were examined. Lastly, we compared anticoagulation, response to treatment, recurrence of PE, and causes of death among groups. By modifying the method of Musset et al. [13], we categorized the deaths on the basis of available information as related to PE (certainly or possibly), not related to PE or unknown.

\section{Radiologic Data}

On CT scan, a PE was diagnosed as a sharply delineated pulmonary arterial filling defect present in at least 2 consecutive image sections and located centrally within the vessel or with acute angles at the interface with the vessel wall [14]. A DVT was defined as a low-attenuating partial or complete intraluminal filling defect surrounded by a high-attenuating ring of enhanced blood that was seen on at least 2 consecutive transverse images [15]. A proximal DVT was defined as a thrombosis at the level of the popliteal vein or above and a distal DVT as a thrombosis affecting the axial calf veins. The changes in the PE upon follow-up CT scan were classified as follows [16]: (1) normalization, when no PE was identified; (2) improvement, if the PE was remarkably reduced in size and/or extent; (3) no change, if no remarkable change was noted; (4) aggravation, when the size and/or extent of the PE had progressed; and (5) undetermined, when objective assessment was difficult.

CT scans were performed using MDCT scanners with 16 detector rows (Light Speed 16; General Electric, Milwaukee, Wisc., USA) or with 64 detector rows (Aquilion 64; Toshiba Medical System, Tokyo, Japan). The scan was obtained in the craniocaudal direction during a single inspiratory breath hold, ranging from the apex to the diaphragm. The CT parameters used were $120 \mathrm{kVp}$ and a $0.75-\mathrm{mm}$ collimation with a pitch $<1.5$. Low osmolar nonionic contrast material $(2 \mathrm{ml} / \mathrm{kg}$; up to $150 \mathrm{ml})$ was injected through an arm vein at 3-4 ml/s. Individual contrast optimization was achieved using bolus tracking within the main pulmonary artery. Indirect CT venography was performed from the diaphragm to the ankles to detect DVT 140 s after a thoracic scan.

\section{Statistical Analysis}

Statistical analyses were performed using SPSS software, version 12.0 (SPSS Inc., Chicago, Ill., USA). The data are expressed as the mean \pm standard deviation or the median with interquartile range for continuous variables and percentages for categorical variables. Among the groups, the continuous variables were compared by 1-way analysis of variance (ANOVA) and the KruskalWallis test if non-normally distributed. In multiple comparisons, Scheffe's and Tukey's methods were used as a post-hoc test if equal variances were assumed and Dunnett's T3 method was adopted if equal variances were not assumed. Categorical variables were compared using a $\chi^{2}$ test among groups and Bonferroni's correction was used as a post-hoc follow-up test. To summarize the survival of the patients, we used the Kaplan-Meier test to construct survival curves, which were then compared with the results of log-rank tests. 

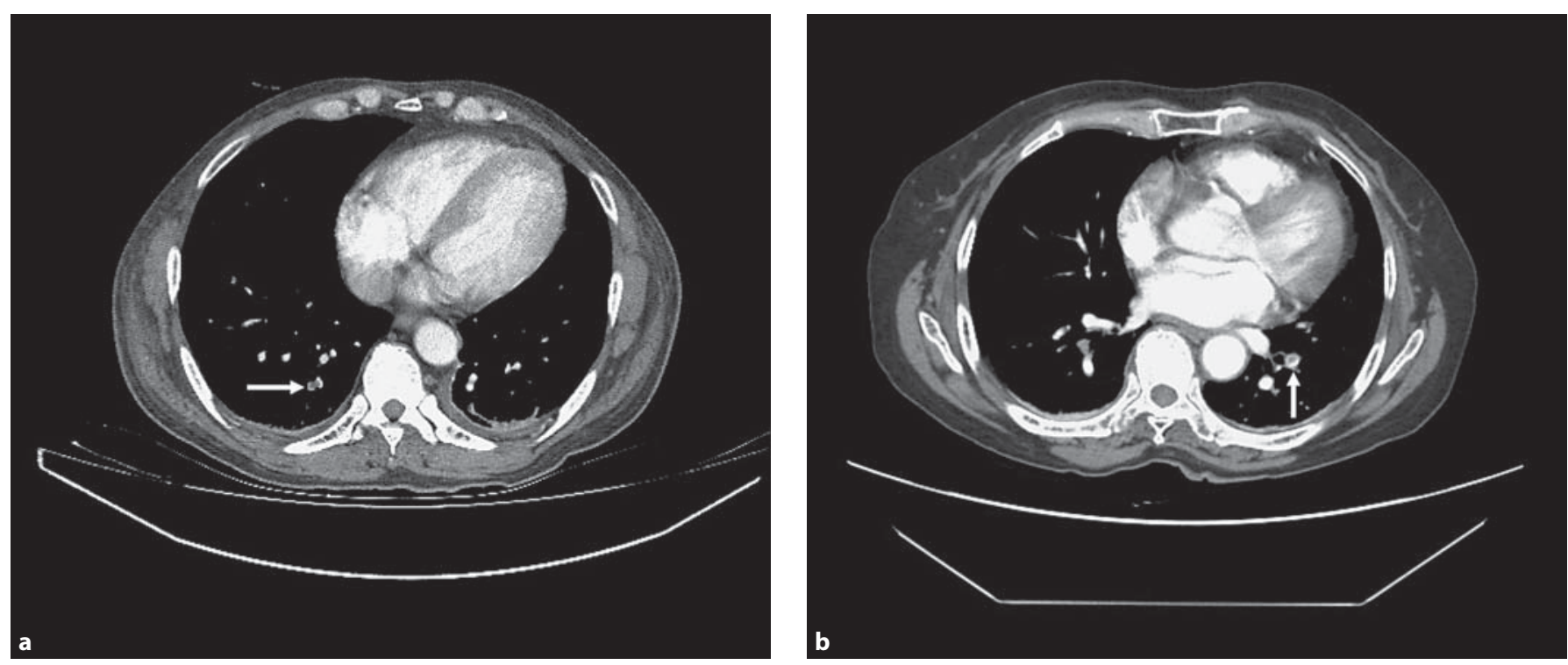

Fig. 1. Computed tomographic pulmonary angiography demonstrated emboli in the sub-segmental (a, arrow), segmental (b, arrow), and right and left pulmonary arteries (c, arrowheads) along with lobar pulmonary artery (c, arrow).

\section{Results}

\section{Demographic Characteristics}

The demographic data are summarized in table 1 . The central group included 245 patients ( $73.4 \%$ of the total), the segmental group contained 67 patients (20.1\%) and the sub-segmental group had 22 patients (6.6\%). Gender and smoking history (prevalence of ever-smokers and pack-years) did not significantly differ among these groups. There was a significant difference in BMI among the 3 groups $(\mathrm{p}=0.038)$ but in the post-hoc test, the central group just had a tendency for a higher BMI than the

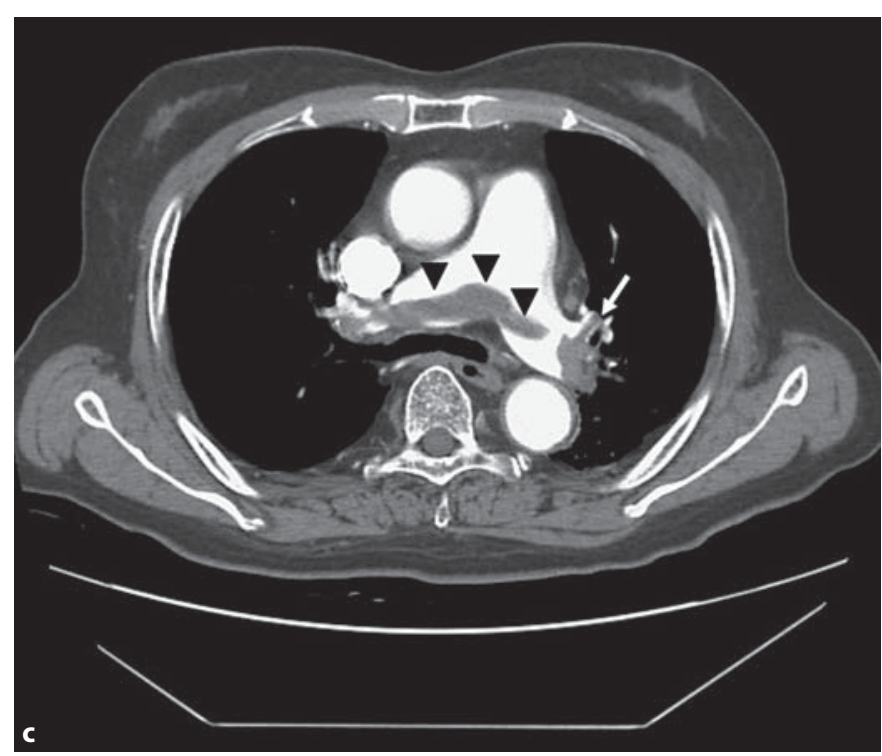

sub-segmental group ( $\mathrm{p}=0.073$ by Scheffe's method and $\mathrm{p}=0.058$ by Tukey's method).

In the sub-segmental and segmental groups, the patients presented most frequently with incidental CT findings (63.6 and 53.7\%, respectively), dyspnea (18.2 and $23.9 \%$, respectively) and leg pain or swelling (13.6 and $20.9 \%$, respectively). The most common presenting manifestation of the central group was dyspnea (48.8\%), followed by incidental CT findings (18.8\%) and leg pain or swelling (18.3\%). No significant differences in the clinical probability scores (Wells and Revised Geneva scores) were noted among the groups. However, according to the 
Table 1. PE patient demographics $(n=334)$

\begin{tabular}{|c|c|c|c|c|}
\hline & $\begin{array}{l}\text { Sub-segmental } \\
(\mathrm{n}=22)\end{array}$ & $\begin{array}{l}\text { Segmental } \\
(\mathrm{n}=67)\end{array}$ & $\begin{array}{l}\text { Central } \\
(\mathrm{n}=245)\end{array}$ & $\mathrm{p}$ value \\
\hline Age, years & $70(52-72)$ & $65(42-63)$ & $66(53-71)$ & 0.677 \\
\hline Male gender & $10(45.5)$ & $34(50.7)$ & $110(44.9)$ & 0.695 \\
\hline \multicolumn{5}{|l|}{ Smoking history } \\
\hline Ever-smokers & $7 / 20(35.0)$ & $24 / 64(37.5)$ & $86 / 243(35.4)$ & 0.949 \\
\hline Pack years & $40(25-40)$ & $30(18-50)$ & $30(13-40)$ & 0.282 \\
\hline Body mass index & $21(19-24)$ & $24(22-25)$ & $24(22-26)$ & $0.038^{\mathrm{a}}$ \\
\hline Presenting manifestations & & & & $<0.001$ \\
\hline Dyspnea & $4(18.2)$ & $16(23.9)$ & $117(48.8)$ & \\
\hline Chest pain & - & $1(1.5)$ & $31(12.9)$ & \\
\hline Hemoptysis & $1(4.5)$ & - & $3(1.3)$ & \\
\hline Leg pain or swelling & $3(13.6)$ & $14(20.9)$ & $44(18.3)$ & \\
\hline Incidental CT finding & $14(63.6)$ & $36(53.7)$ & $45(18.8)$ & \\
\hline Duration of symptoms, days & $6(3-20)$ & $5(2-21)$ & $3(1-8)$ & 0.280 \\
\hline Wells score & $2(0-4)$ & $2(1-4)$ & $2(1-5)$ & 0.115 \\
\hline Simplified clinical probability & & & & 0.056 \\
\hline PE likely & $2(9.1)$ & $11(16.4)$ & $59(24.1)$ & \\
\hline PE unlikely & $20(90.9)$ & $56(83.6)$ & $186(75.9)$ & \\
\hline Revised Geneva score & $6(2-12)$ & $6(4-8)$ & $6(4-8)$ & 0.447 \\
\hline Deep vein thrombosis & $9(40.9)$ & $41(61.2)$ & $177(72.2)$ & $0.004^{\mathrm{b}}$ \\
\hline Distal & $6(27)$ & $20(30)$ & $61(25)$ & 0.709 \\
\hline Proximal & $3(14)$ & $21(31)$ & $116(47)$ & $0.001^{\mathrm{c}}$ \\
\hline
\end{tabular}

Data are presented as median (range), $\mathrm{n}(\%)$ or $\mathrm{n} / \mathrm{N}(\%)$.

Multiple comparison: ${ }^{a}$ sub-segmental vs. central, $p=0.073$ (Scheffe's method) and $p=0.058$ (Tukey's method); ${ }^{b}$ sub-segmental vs. central, Bonferroni's corrected $\mathrm{p}=0.002 ;{ }^{\mathrm{c}}$ sub-segmental vs. central, Bonferroni's corrected $\mathrm{p}=0.003$.

simplified Wells rule, PE-likely frequency tended to be higher in the central group, as compared to the segmental and sub-segmental groups ( $\mathrm{p}=0.056)$.

Statistically significant differences in the prevalence of co-existing DVTs were noted among the 3 groups ( $\mathrm{p}=$ 0.004). DVTs were less frequently observed in the subsegmental group than in the central group (Bonferroni's corrected $\mathrm{p}=0.002)$; in the remaining comparisons, significant differences were not found. Likewise, the frequency of proximal DVTs differed significantly among these groups ( $p=0.001)$; in particular, the sub-segmental group had less frequent proximal DVTs compared with the central group (Bonferroni's corrected $\mathrm{p}=0.001$ ). However, there was no significant difference in the prevalence of distal DVTs among the groups.

\section{Risk Factors and Comorbidities of Pulmonary \\ Embolism}

Distributions of risk factors and comorbid conditions of PEs are presented in table 2. The frequency of surgery or trauma was higher in the sub-segmental and segmen- tal groups (Bonferroni's corrected $\mathrm{p}<0.001$, respectively) as compared with the central group. The prevalence of accompanying malignancy significantly differed among the 3 groups $(\mathrm{p}=0.021)$, but the Bonferroni's corrected $\mathrm{p}$ value of any pair did not reach statistical significance. No significant differences in the remaining risk factors and comorbid illnesses among the groups were observed.

\section{Laboratory Findings of Pulmonary Embolism}

The segmental group had significantly lower NT-proBNP, CK-MB and troponin-I levels than the central group $(\mathrm{p}<0.001, \mathrm{p}<0.001$ and $\mathrm{p}=0.001$, respectively), unlike the sub-segmental group (table 3 ). However, the sub-segmental group had significantly higher $\mathrm{PaO}_{2}$ and $\mathrm{SaO}_{2}$ values and a lower $\mathrm{P}(\mathrm{A}-\mathrm{a}) \mathrm{O}_{2}$, as compared with the central group ( $\mathrm{p}<0.05$, respectively). T-wave inversion on the precordial leads of ECG differed significantly among the 3 groups ( $p<0.001$ ); this change on ECG was more common in the segmental group compared with the central group (Bonferroni's corrected $\mathrm{p}<0.001$ ). RV dysfunction on echocardiography was observed only in the central 
Table 2. Risk factors of pulmonary embolism and comorbidities

\begin{tabular}{|c|c|c|c|c|}
\hline & $\begin{array}{l}\text { Sub-segmental } \\
(\mathrm{n}=22)\end{array}$ & $\begin{array}{l}\text { Segmental } \\
(\mathrm{n}=67)\end{array}$ & $\begin{array}{l}\text { Central } \\
(\mathrm{n}=245)\end{array}$ & $\begin{array}{l}\mathrm{p} \\
\text { value }\end{array}$ \\
\hline Past history of venous thromboembolism & $2(9.1)$ & $2(3.0)$ & $12(4.9)$ & 0.474 \\
\hline Surgery or trauma & $14(63.6)$ & $28(41.8)$ & $44(18.0)$ & $<0.001^{\mathrm{a}}$ \\
\hline Malignancy & $2(9.1)$ & $23(34.3)$ & $51(20.8)$ & 0.021 \\
\hline Immobilization $^{1}$ & $6(27.3)$ & $13(19.4)$ & $55(22.4)$ & 0.726 \\
\hline Obesity $(\mathrm{BMI}>30)$ & - & $2(3.0)$ & $3(1.2)$ & 1.000 \\
\hline Pregnancy or postpartum & - & - & $3(1.2)$ & 1.000 \\
\hline Varicose vein & - & $1(1.5)$ & $1(0.4)$ & 0.463 \\
\hline Neurologic disorder ${ }^{2}$ & $3(13.6)$ & $1(1.5)$ & $19(7.8)$ & 0.057 \\
\hline Atherosclerosis obliterans & - & $1(1.5)$ & $1(0.4)$ & 0.463 \\
\hline Arthritis ${ }^{3}$ & $1(4.5)$ & $1(1.5)$ & $10(4.1)$ & 0.567 \\
\hline Collagen vascular disorders & $1(4.5)$ & - & $4(1.6)$ & 0.233 \\
\hline Myeloproliferative disorders ${ }^{4}$ & - & $1(1.5)$ & $1(0.4)$ & 0.463 \\
\hline Chronic lung diseases ${ }^{5}$ & $17(6.9)$ & $6(9)$ & $4(18.2)$ & 0.129 \\
\hline Pulmonary tuberculosis or NTM infection & $2(9.1)$ & $3(4.5)$ & $13(9.1)$ & 0.576 \\
\hline Pneumonia or lung abscess & - & $2(3)$ & $4(1.6)$ & 0.743 \\
\hline Cardiovascular disorders ${ }^{6}$ & $1(4.5)$ & $5(7.5)$ & $24(9.8)$ & 0.747 \\
\hline Chronic liver diseases & $1(4.5)$ & $2(3)$ & $3(1.2)$ & 0.213 \\
\hline Chronic renal diseases ${ }^{7}$ & $1(4.5)$ & - & $6(2.4)$ & 0.204 \\
\hline Dyslipidemia & - & - & $5(2.0)$ & 0.708 \\
\hline Hypertension & $6(27.3)$ & $15(22.4)$ & $80(32.7)$ & 0.256 \\
\hline Diabetes & $6(27.3)$ & $14(20.9)$ & $41(16.7)$ & 0.389 \\
\hline Other endocrine disorders ${ }^{8}$ & - & - & $5(2.0)$ & 0.708 \\
\hline Tetanus, burn, or bullous pemphigoid & - & $1(4.5)$ & $6(2.4)$ & 1.000 \\
\hline
\end{tabular}

\footnotetext{
$\mathrm{NTM}=$ nontuberculous mycobacteria. Data are presented as n (\%).

a Sub-segmental vs. central, Bonferroni's corrected $\mathrm{p}<0.001$; segmental vs. central, Bonferroni's corrected $\mathrm{p}<0.001$.

${ }^{1}$ Bed rest within past month for most of the day for $\geq 3$ consecutive days; ${ }^{2}$ cerebrovascular accident, dementia, Parkinson's disease, or hydrocephalus; ${ }^{3}$ rheumatoid arthritis, osteoarthirits, or gout; ${ }^{4}$ polycythemia vera or essential thrombocytosis; ${ }^{5}$ chronic obstructive pulmonary disease, asthma, tuberculosis-destroyed lung, bronchiectasis, or idiopathic pulmonary fibrosis; ${ }^{6}$ congestive heart failure, ischemic heart disease, atrial fibrillation, or aortic dissection; ${ }^{7}$ chronic renal failure or nephrotic syndrome; ${ }^{8}$ Graves' disease, hypothyroidism, Cushing syndrome, or pheochromocytoma.
}

group ( $\mathrm{p}=0.039)$, but no individual pairing achieved statistical significance in multiple comparisons.

\section{Anticoagulation, Treatment Outcome and Clinical Course}

The proportion of patients who received anticoagulation therapy was as follows: central, $93.5 \%(\mathrm{n}=229)$; segmental, $80.6 \%(\mathrm{n}=54)$, and sub-segmental, 68.2\% ( $\mathrm{n}=$ 15). The sub-segmental and segmental groups underwent anticoagulation less frequently, as compared with the central group (Bonferroni's corrected $\mathrm{p}<0.001$ and $\mathrm{p}=$ 0.001 , respectively; fig. $2 \mathrm{a}$ ). Statistically significant differences in the causes of non-anticoagulation were not noted among the groups ( $p=0.141$; fig. $2 b)$. In the sub-segmental group, the most common cause of non-antico- agulation was missed diagnosis, in contrast with a poor general condition or refusal of anticoagulation in the segmental group and contraindications of anticoagulation in the central group.

Of patients who underwent follow-up CT scans, the proportion of normalization or improvement did not differ significantly among the 3 groups (central, segmental and sub-segmental): $93.7 \%$ (104/111), 90.0\% (27/30) and $100 \%$ (9/9), respectively. The median duration of followup was 8 months (IQR 3-19 months). PE recurred only in the central group $(2.4 \%, \mathrm{n}=6)$. No significant differences in overall survival among the 3 groups were found $(\mathrm{p}=0.052$; fig. $3 \mathrm{a})$. There was also no statistically significant difference in PE-related deaths among the groups $(\mathrm{p}=0.662$; fig. $3 \mathrm{~b})$. However, PE-related deaths were not 

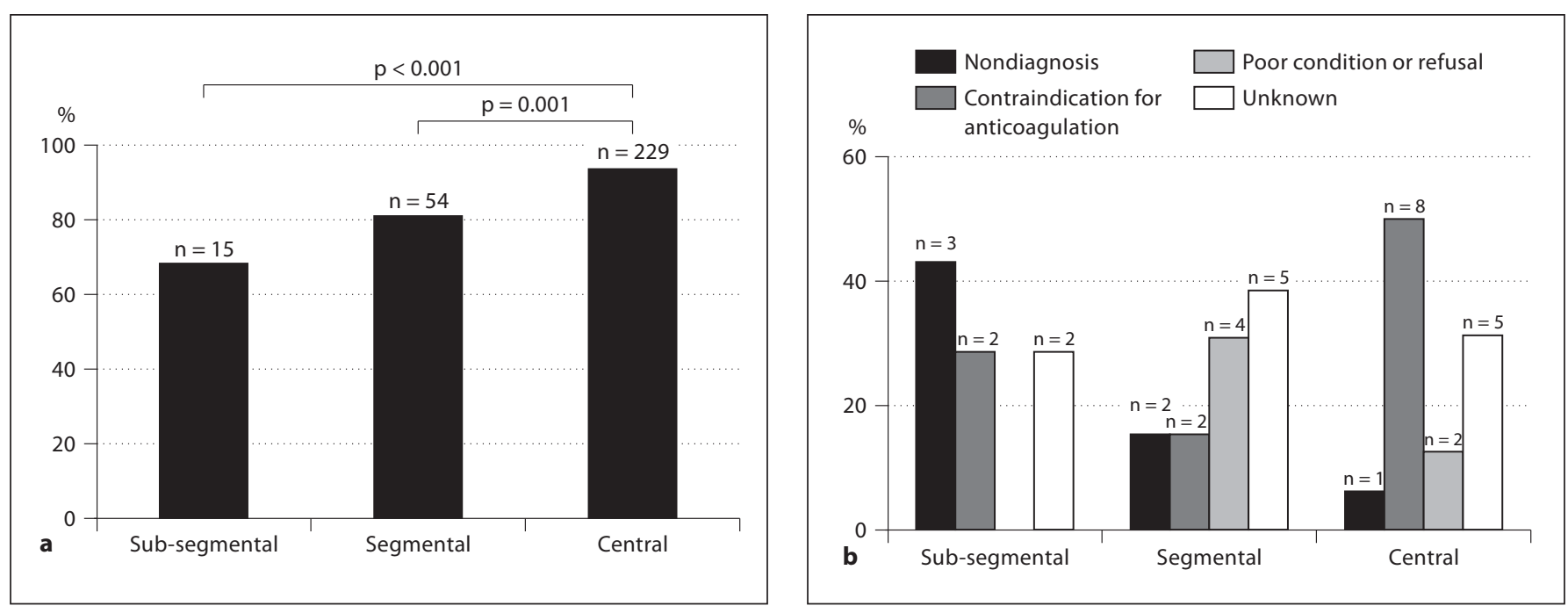

Fig. 2. a The frequency of anticoagulation in each group. The sub-segmental (68.2\%) and segmental (80.6\%) groups underwent anticoagulation less frequently, as compared with the central group (93.5\%). b Causes of nonanticoagulation in each group. Missed diagnosis was the most common cause of non-anticoagulation in the sub-segmental group, as opposed to a poor general condition or refusal of anticoagulation in the segmental group and contraindications of anticoagulation in the central group.

Table 3. Laboratory findings of pulmonary embolism

\begin{tabular}{|c|c|c|c|c|}
\hline & Sub-segmental & Segmental & Central & $\mathrm{p}$ value \\
\hline Hypotension & $0 / 21(0.0)$ & $1 / 65(1.5)$ & $9 / 242(3.7)$ & 0.844 \\
\hline D-dimer, ug/l & $748(410-759 ; \mathrm{n}=13)$ & $771(212-1,234 ; \mathrm{n}=38)$ & $719(331-1,162 ; \mathrm{n}=174)$ & 0.780 \\
\hline NT-proBNP, pg/ml & $140(89-4,956 ; \mathrm{n}=12)$ & $81(25-966 ; \mathrm{n}=22)$ & $693(210-3,425 ; \mathrm{n}=134)$ & $<0.001^{\mathrm{a}}$ \\
\hline $\mathrm{CK}-\mathrm{MB}, \mathrm{ng} / \mathrm{ml}$ & $0.3(0.4-6.2 ; \mathrm{n}=14)$ & $0.5(0.3-1.2 ; \mathrm{n}=40)$ & $1.0(0.6-2.7 ; \mathrm{n}=175)$ & $<0.001^{\mathrm{a}}$ \\
\hline Troponin-I, ng/ml & $0.04(0.04-0.90 ; \mathrm{n}=14)$ & $0.04(0.03-0.05 ; \mathrm{n}=39)$ & $0.06(0.03-0.22 ; \mathrm{n}=178)$ & $0.002^{\mathrm{b}}$ \\
\hline $\mathrm{PaO}_{2}, \mathrm{~mm} \mathrm{Hg}$ & $85.3 \pm 12.2(\mathrm{n}=13)$ & $77.0 \pm 16.8(\mathrm{n}=31)$ & $72.4 \pm 15.5(\mathrm{n}=159)$ & $0.009^{c}$ \\
\hline $\mathrm{SaO}_{2}, \%$ & $97(96-99 ; \mathrm{n}=13)$ & $96(92-97 ; \mathrm{n}=31)$ & $96(93-97 ; \mathrm{n}=159)$ & $0.024^{\mathrm{c}}$ \\
\hline $\mathrm{P}(\mathrm{A}-\mathrm{a}) \mathrm{O}_{2}, \mathrm{~mm} \mathrm{Hg}$ & $26(38-61 ; \mathrm{n}=13)$ & $34.5(27-72 ; \mathrm{n}=31)$ & $47(24-62 ; \mathrm{n}=159)$ & $0.046^{\mathrm{c}}$ \\
\hline T-wave inversion on precordial leads & $1 / 16(6.3)$ & $2 / 48(4.2)$ & $65 / 211(30.8)$ & $<0.001^{\mathrm{d}}$ \\
\hline RV dysfunction on echocardiography & $0 / 4(0.0)$ & $0 / 9(0.0)$ & $34 / 103(33)$ & 0.039 \\
\hline
\end{tabular}

NT-proBNP = N-terminal-pro-B-type natriuretic peptide; $\mathrm{CK}-\mathrm{MB}=$ creatine kinase- $\mathrm{MB} ; \mathrm{PaO}_{2}=$ partial pressure of oxygen in arterial blood; $\mathrm{SaO}_{2}=$ oxygen saturation in arterial blood; $\mathrm{P}(\mathrm{A}-\mathrm{a}) \mathrm{O}_{2}=$ alveolar-arterial oxygen difference; $\mathrm{RV}=$ right ventricle. Data are presented as mean $\pm \mathrm{SD}$, median (range) or $\mathrm{n} / \mathrm{N}(\%)$.

${ }^{a}$ Segmental vs. central, $\mathrm{p}<0.001 ;{ }^{\mathrm{b}}$ segmental vs. central, $\mathrm{p}=0.001 ;{ }^{\mathrm{c}}$ sub-segmental vs. central, $\mathrm{p}<0.05 ;{ }^{\mathrm{d}}$ segmental vs. central, Bonferroni's corrected $\mathrm{p}<0.001$.

noted in the sub-segmental group in contrast to 7 (2.9\%) and $3(4.5 \%)$ deaths in the central and segmental groups, respectively. All 3 patients from the segmental groups had aggravation of dyspnea and hypoxia during in-hospital stay and had serious comorbid conditions, including advanced gall bladder cancer with peritoneal carcinomatosis, extensive stage small cell lung cancer and bedridden status due to cerebral infarction.

Peripheral Pulmonary Embolism

\section{Discussion}

The present study was primarily focused on the clinical characteristics of peripheral PEs, particularly ISSPEs. Like the segmental group, the patients of the sub-segmental group presented most commonly with incidental CT findings, and proximal DVTs were less commonly found in this group as compared to the central group. 

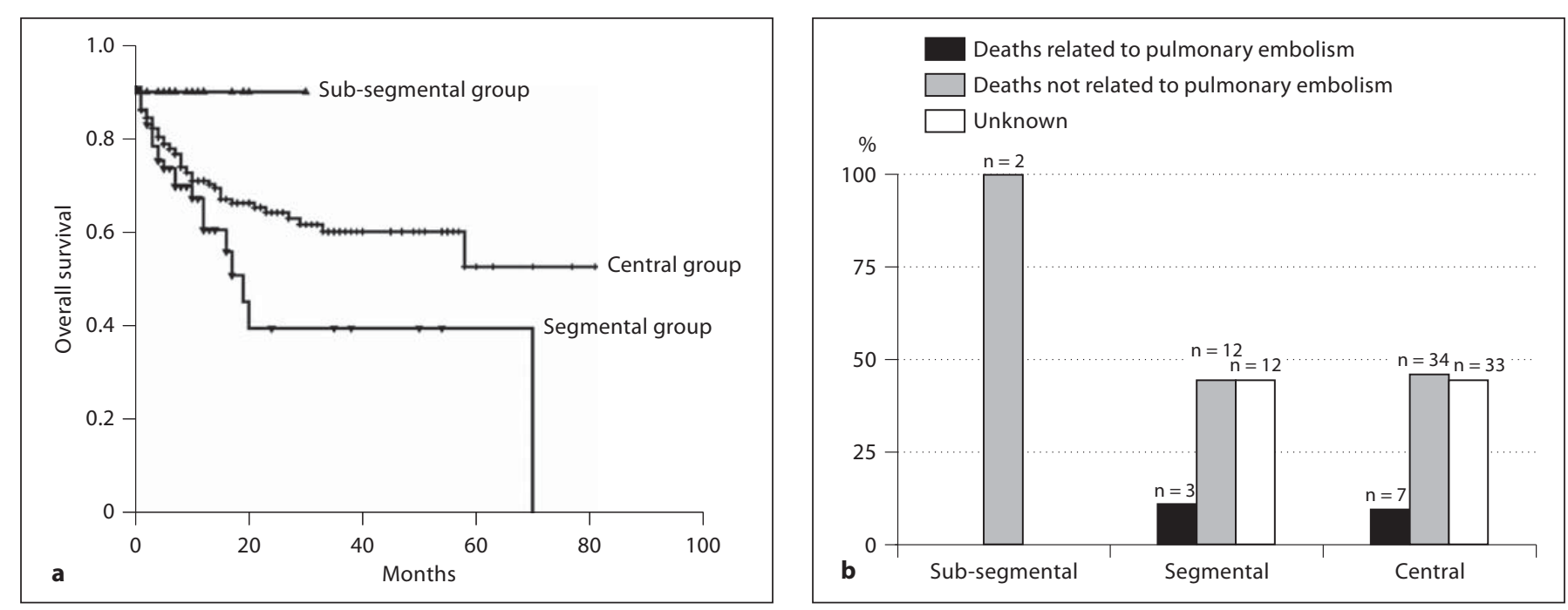

Fig. 3. a No significant differences in overall survival among the 3 groups were found $(p=0.052)$. $\mathbf{b}$ No patient died of PE-related causes in the sub-segmental group.

There were no significant differences in the risk factors of PEs and comorbid illnesses among the groups except for surgery or trauma, which accompanied the sub-segmental group more frequently as compared with the central type. The patients with PE limited to segmental or sub-segmental arteries had lower serum levels of biomarkers and less frequent ECG change of RV strain or more preserved oxygenation levels [higher $\mathrm{PaO}_{2}$ and $\mathrm{SaO}_{2}$ and lower $\left.\mathrm{P}(\mathrm{A}-\mathrm{a}) \mathrm{O}_{2}\right]$, when compared to those with the central type. Moreover, hypotension and RV dysfunction on echocardiography were not observed in the sub-segmental group, suggesting that ISSPE patients may be hemodynamically stable. Although approximately $30 \%$ of the sub-segmental group did not undergo anticoagulation, there was no case of death related to or recurrence of PE.

The prevalence of ISSPE was $6.6 \%$ in this study, which is similar to the $6 \%$ in an analysis of 383 pulmonary angiograms from the PIOPED study [17] and $4.2-27.9 \%$ reported in the literature using MDCT [7, 9, 17-21]. Extracted from the data of PIOPED II, typical presentations of PE (hemoptysis/pleuritic pain, uncomplicated dyspnea or circulatory collapse) were less common in patients with segmental PEs compared to patients with PEs in more proximal arteries [22]. As described above [5], the patients with ISSPE had less dyspnea, and less frequently had a high clinical probability of PE. Similarly, the most common presentation of peripheral PEs was an incidental CT finding unlike the central group. However, the
Wells and Revised Geneva scores were similar among the groups, although PE-likely patients tended to be more common in the central group, as compared to small PE groups. These may result from the fact that a considerable number of asymptomatic PE patients $(\mathrm{n}=95,28 \%)$ were included in the present study.

Of comorbid conditions and risk factors for PE, trauma or surgery and malignancy differed among the groups. The sub-segmental group was more frequently accompanied by trauma or surgery than the central group. This can be explained partly by the finding that PE was more often incidentally detected on CT scan after trauma or surgery as compared to the remaining cases (72.1 vs. $13.3 \%, p<0.001)$. In contrast, the frequency of malignancy did not achieve statistical significance in the posthoc tests.

Patients with PE limited to small peripheral arteries appear to have a more benign clinical presentation than patients with proximal PE $[5,23]$. Similarly, the present study revealed that the segmental group exhibited lower levels of serologic biomarkers and a lower incidence of ECG changes of RV strain when compared with the central group. However, we do not know the reason why these statistical differences were not noted between the sub-segmental and central groups, considering that comorbid conditions, such as heart diseases, did not differ among the groups. It is noteworthy that hypotension and echocardiographic RV dysfunction did not develop in the sub-segmental group. Compared to the central group, the 
sub-segmental group had co-existing proximal DVTs less commonly (14 vs. $47 \%$ ) but not as rarely as that in a previous report (3.3 vs. $43.8 \%$ ) [5]. The severity of PE should be understood as an individual estimate of PE-related fatality rather than the anatomical burden of pulmonary emboli [24]. In this context, combined DVT, in particular proximal DVT, is considered to be an independent risk factor of poor outcome of PE [25], although recurrence of venous thromboembolism and PE-related deaths did not differ among the 3 groups in the present study.

Recurrence of PEs did not occur in the segmental and sub-segmental groups, in contrast to $2.4 \%$ in the central group. Furthermore, none of the patients in the sub-segmental group died from PE-related causes. These results suggest that otherwise healthy individuals with ISSPEs may not be at a significantly increased risk for morbidity and mortality in accordance with a previous report [26]. As mentioned above, 7 of 22 patients did not receive anticoagulant in the sub-segmental group and none of this group experienced recurrence of $\mathrm{PE}$ and $\mathrm{PE}$-related deaths irrespective of anticoagulation. This implies that missing of ISSPEs does not seem to adversely affect patient outcome. This can be explained by the fact that small emboli may be dissolved by intrinsic fibrinolytic activity from the lung vasculature [27]. The necessity to treat patients with ISSPEs cannot be answered in this study, similarly to previous studies [5].

In the segmental group, however, PE-related deaths $(\mathrm{n}=3,4.5 \%)$ occurred. Each of the 3 patients experienced sudden clinical deterioration, circulatory collapse and death during in-hospital stay, although emboli did not extend beyond segmental pulmonary arteries on the initial CT scan. Considering this difference, the clinical course of the PE limited to segmental arteries may be different from ISSPE. Moreover, cardiopulmonary reserve is more likely to have influenced the prognosis of these patients, although pulmonary emboli were small.

Our study had several limitations. First, since our study was performed retrospectively, a selection bias could not be avoided. Second, as the patients were recruited from the database with a PE-positive CT scan, suspected PE and incidentally detected PE cases were included. Unsuspected PE patients with less severe clinical manifestations were likely to influence the differences of the clinical characteristics by the largest PE-involved pulmonary arteries. Third, there is a possibility of underestimation of small PE because we did not review negative CT images. Lastly, whether CT-based ISSPEs are true PEs remains questionable [28]. True positivity of PE on CT scan can be supported by the following criteria: (1) normalization or improvement of PE on follow-up CT scans $(\mathrm{n}=9)$; (2) CT-matching defects on perfusion scan (1/7) [28]; (3) coexisting DVT on CT venography $(n=9)$ or ultrasound [26], and (4) multiplicity of pulmonary emboli on CT scan $(n=12)$ [29]. Overall, of 22 ISSPE patients, 17 (77\%) had findings supportive of PE.

In conclusion, the most common presentation is the incidental CT finding in the peripheral PE. Patients with ISSPE may have a more benign clinical presentation, as compared to the central type, and may take a good clinical course without mortality and recurrence.

\section{References}

1 Remy-Jardin M, Remy J, Wattinne L, Giraud F: Central pulmonary thromboembolism: diagnosis with spiral volumetric CT with the single-breath-hold technique-comparison with pulmonary angiography. Radiology 1992; 185:381-387.

-2 Mullins MD, Becker DM, Hagspiel KD, Philbrick JT: The role of spiral volumetric computed tomography in the diagnosis of pulmonary embolism. Arch Intern Med 2000; 160:293-298.

-3 Rathbun SW, Raskob GE, Whitsett TL: Sensitivity and specificity of helical computed tomography in the diagnosis of pulmonary embolism: a systematic review. Ann Intern Med 2000;132:227-232.
4 Ghaye B, Szapiro D, Mastora I, Delannoy V, Duhamel A, Remy J, Remy-Jardin M: Peripheral pulmonary arteries: how far in the lung does multi-detector row spiral CT allow analysis? Radiology 2001;219:629-636.

5 Le Gal G, Righini M, Parent F, van Strijen M, Couturaud F: Diagnosis and management of sub-segmental pulmonary embolism. J Thromb Haemost 2006;4:724-731.

-6 Schoepf UJ, Kessler MA, Rieger CT, Herzog P, Klotz E, Wiesgigl S, Becker CR, Exarhos DN, Reiser MF: Multislice CT imaging of pulmonary embolism. Eur Radiol 2001;11: 2278-2286.

-7 Nazaroglu H, Ozmen CA, Akay HO, Kilinc I, Bilici A: 64-MDCT pulmonary angiography and CT venography in the diagnosis of thromboembolic disease. Am J Roentgenol 2009;192:654-661. $\checkmark 8$ Diffin DC, Leyendecker JR, Johnson SP, Zucker RJ, Grebe PJ: Effect of anatomic distribution of pulmonary emboli on interobserver agreement in the interpretation of pulmonary angiography. Am J Roentgenol 1998;171:1085-1089.

-9 Thomeer MG, Pattynama PM, Hartmann IJ, Kieft GJ, Van Strijen MJ: High incidence of isolated sub-segmental pulmonary emboli on multi-slice spiral CT: a comparative clinical study. Thromb Haemost 2006;95:914915.

10 Goodman LR: Small pulmonary emboli: what do we know? Radiology 2005;234:654658 . 
11 Wells PS, Anderson DR, Rodger M, Stiell I, Dreyer JF, Barnes D, Forgie M, Kovacs G, Ward J, Kovacs MJ: Excluding pulmonary embolism at the bedside without diagnostic imaging: management of patients with suspected pulmonary embolism presenting to the emergency department by using a simple clinical model and D-dimer. Ann Intern Med 2001;135:98-107.

-12 Le Gal G, Righini M, Roy PM, Sanchez O, Aujesky D, Bounameaux H, Perrier A: Prediction of pulmonary embolism in the emergency department: the Revised Geneva score. Ann Intern Med 2006;144:165-171.

13 Musset D, Parent F, Meyer G, Maitre S, Girard $\mathrm{P}$, Leroyer C, Revel MP, Carette MF, Laurent M, Charbonnier B, Laurent F, Mal H, Nonent M, Lancar R, Grenier P, Simonneau G: Diagnostic strategy for patients with suspected pulmonary embolism: a prospective multicentre outcome study. Lancet 2002; 360:1914-1920.

-14 Gladish GW, Choe DH, Marom EM, Sabloff BS, Broemeling LD, Munden RF: Incidental pulmonary emboli in oncology patients: prevalence, CT evaluation, and natural history. Radiology 2006;240:246-255.

-15 Cham MD, Yankelevitz DF, Shaham D, Shah AA, Sherman L, Lewis A, Rademaker J, Pearson G, Choi J, Wolff W, Prabhu PM, Galanski M, Clark RA, Sostman HD, Henschke CI: Deep venous thrombosis: detection by using indirect CT venography: the pulmonary angiography-indirect CT venography cooperative group. Radiology 2000;216:744-751.

-16 Lee JW, Cha SI, Jung CY, Choi WI, Jeon KN, Yoo SS, Kim CH, Park JY, Jung TH: Clinical course of pulmonary embolism in lung cancer patients. Respiration 2009;78:42-48.
7 Stein PD, Henry JW: Prevalence of acute pulmonary embolism in central and sub-segmental pulmonary arteries and relation to probability interpretation of ventilation/ perfusion lung scans. Chest 1997;111:12461248.

18 Perrier A, Roy PM, Sanchez O, Le Gal G, Meyer G, Gourdier AL, Furber A, Revel MP, Howarth N, Davido A, Bounameaux H: Multidetector-row computed tomography in suspected pulmonary embolism. N Engl J Med 2005;352:1760-1768.

-19 Nijkeuter M, Kwakkel-van Erp JM, Kruip MJ, Sohne M, Buller HR, Leebeek FW, Huisman MV: Incidence of diagnosis of sub-segmental pulmonary emboli using multidetector row and single-detector row computed tomography. J Thromb Haemost 2008; 6: 384-386.

20 Eyer BA, Goodman LR, Washington L: Clinicians' response to radiologists' reports of isolated sub-segmental pulmonary embolism or inconclusive interpretation of pulmonary embolism using MDCT. Am J Roentgenol 2005;184:623-628.

21 Coche E, Verschuren F, Keyeux A, Goffette P, Goncette L, Hainaut P, Hammer F, Lavenne E, Zech F, Meert P, Reynaert MS: Diagnosis of acute pulmonary embolism in outpatients: Comparison of thin-collimation multi-detector row spiral CT and planar ventilationperfusion scintigraphy. Radiology 2003;229: 757-765.

22 Stein PD, Beemath A, Matta F, Weg JG, Yusen RD, Hales CA, Hull RD, Leeper KV Jr, Sostman HD, Tapson VF, Buckley JD, Gottschalk A, Goodman LR, Wakefied TW, Woodard PK: Clinical characteristics of patients with acute pulmonary embolism: data from PIOPED II. Am J Med 2007;120:871-879.
23 Bulbul Y, Ozsu S, Kosucu P, Oztuna F, Ozlu T, Topbaș M: Time delay between onset of symptoms and diagnosis in pulmonary thromboembolism. Respiration 2009;78:3641.

24 Torbicki A, Perrier A, Konstantinides S, Agnelli G, Galie N, Pruszczyk P, Bengel F, Brady AJB, Ferreira D, Janssens U, Klepetko W, Mayer E, Remy-Jardin M, Bassand JP: Guidelines on the diagnosis and management of acute pulmonary embolism. Eur Heart J 2008;29:2276-2315.

25 Yamaki T, Nozaki M, Sakurai H, Takeuchi M, Soejima K, Kono T: Presence of lower limb deep vein thrombosis and prognosis in patients with symptomatic pulmonary embolism: preliminary report. Eur J Vasc Endovasc Surg 2009;37:225-231.

-26 Wildberger JE, Mahnken AH, Das M, Kuttner A, Lell M, Gunther RW: CT imaging in acute pulmonary embolism: diagnostic strategies. Eur Radiol 2005; 15:919-929.

$\checkmark 27$ Kroegel C, Reissig A: Principle mechanisms underlying venous thromboembolism: epidemiology, risk factors, pathophysiology and pathogenesis. Respiration 2003;70:7-30.

28 Stein PD, Fowler SE, Goodman LR, Gottschalk A, Hales CA, Hull RD, Leeper KV Jr, Popovich J Jr, Quinn DA, Sos TA, Sostman HD, Tapson VF, Wakefield TW, Weg JG, Woodard PK: Multidetector computed tomography for acute pulmonary embolism. $\mathrm{N}$ Engl J Med 2006;354:2317-2327.

29 Nijkeuter M, Kwakkel-Van Erp JM, Kruip MJHA, Sohne M, Buller HR, Leebeek FWG, Huisman MV: Incidence of diagnosis of subsegmental pulmonary emboli using multidetector row and single-detector row computed tomography. J Thromb Haemost 2008;6: 384-386. 